\title{
DEVELOPMENT OF THY-1 ANTIGEN ON CEREBELLAR NEURONS IN CULTURE ${ }^{1}$
}

\author{
K. L. FIELDS, ${ }^{*, 2}$ D. N. CURRIE, $\neq^{, 3}$ AND G. R. DUTTON \\ * Departments of Neurology and Neuroscience, Albert Einstein College of Medicine, Bronx, New York 10461, $\neq$ Department of \\ Pharmacology, St. George's Hospital Medical School, London, SW17 ORE, England, and \& Department of Pharmacology, \\ University of Iowa, College of Medicine, Iowa City, Iowa 52242
}

Received February 6, 1981; Revised December 4, 1981; Accepted January 5, 1982

\begin{abstract}
The Thy-1.1 cell surface antigen was demonstrated by indirect immunofluorescence on two types of neurons in dissociated cell cultures of developing rat cerebellum. In cultures from postnatal rats, small cells predominated. They bound tetanus toxin, a neuronal marker, and did not have the capacity to take up $\gamma$-aminobutyric acid (GABA) as measured by autoradiography. From these properties, we conclude that they are granule cells. These neurons began to express the surface antigen Thy- 1.1 by 2 weeks in culture, and by 4 weeks, the antigen was detected on about $40 \%$ of all of the surviving neurons. The second type of neuron, which may be a heterogeneous mixture of cerebellar neurons, was numerous only in cultures prepared from embryonic rats. They were larger than granule cells and expressed Thy-1.1 antigen after a few days in culture. Such cells bound tetanus toxin and were negative for the glial markers galactocerebroside and glial fibrillary acidic protein.

Thy-1-positive cells and cells with high GABA uptake were most frequent in embryonic day 19 cultures, where 40 to $50 \%$ of all of the neurons were positive for either property. They survived about 1 week in culture. The size and frequency of Thy-1 cells and the frequency of similar cells with high GABA uptake suggest that the embryonic rat cultures included many Purkinje cells, which express Thy-1.
\end{abstract}

For cultures of the central nervous system to be of maximal value, a precise identification of the neuronal cells in them is important. The purpose of this report is to show how antisera to a brain membrane antigen, Thy1 , can be used to recognize different classes of cerebellar neurons. Because of the central role of the Purkinje cell in cerebellar function, efforts to promote the survival of this cell in dissociated cultures have been made and are reported here in relation to Thy-1 expression.

Identification of cerebellar neurons in vitro has relied on morphological methods, including Holmes and Golgi

\footnotetext{
'We wish to thank Rod Pigott and Carolyn Haresign for excellent technical assistance and to express our gratitude to our colleagues for generous gifts of antisera, toxin, and aminocyclohexanecarboxylic acid. This work was begun at the Brain Research Group at the Open University and as part of the Neuroimmunology Project at University College, London, which were supported by grants from the British Medical Research Council. Subsequently, the work has been supported by United States Public Health Service Grants NS 14580 and NS 16518.

${ }^{2}$ To whom correspondence should be addressed at Department of Neurology, F-140, Albert Einstein College of Medicine, 1300 Morris Park Avenue, Bronx, NY 10461.

${ }^{3}$ Deceased December 10, 1981.
}

stains (Wolf, 1964; Seil, 1979; Hendelman and Aggerwal, 1980), electron microscopy (Privat and Drian, 1976; Aggerwal and Hendelman, 1980), or recordings of electrical activity with microelectrodes (Nelson and Peacock, 1973; Seil, 1979; Marshall et al., 1980). In explant cultures, areas such as the cerebellar cortex and the deep nuclei may remain separated, which simplifies cell identification, but in dissociated cultures, this property is lost. The mixture of neurons then presents considerable uncertainties in cell identification. The approach that we have used is (1) to limit the brain area to the cerebellum, (2) to utilize neuronal size and frequency for identification, (3) to use the uptake of $\left[{ }^{3} \mathrm{H}\right] \gamma$-aminobutyric acid and autoradiography to distinguish different classes of neurons, (4) to vary the age of the rat in order to favor different neuronal classes, and (5) to utilize immunological markers of neurons and glia.

Cerebellar cortex tissue has clear advantages over neuronal cell cultures from other brain regions. Granule cells outnumber all other cerebellar neurons manyfold in the adult. Even cultures of early postnatal cerebellum are dominated by granule cell neurons (Lasher, 1974; Messer, 1977; Currie and Dutton, 1980). In addition to the granule 
cells, there is a restricted number of other types of neurons, and all of the other neurons of the cortex, small stellate and basket cells as well as large Purkinje and Golgi cells, utilize $\gamma$-aminobutyric acid (GABA) as a neurotransmitter. They have a GABA uptake system such that they can be recognized in culture by autoradiography after exposure to $\left[{ }^{3} \mathrm{H}\right] \mathrm{GABA}$. The perikaryon and processes of all of these cells are labeled heavily, whereas granule cells are not (Lasher, 1974). There are fewer neurons in the deep cerebellar nuclei than there are Purkinje cells ( $\sim 1: 30$, Chan-Palay, 1977), and while some small neurons in the deep nuclei are labeled with $\left[{ }^{3} \mathrm{H}\right] \mathrm{GABA}$, the large neurons are not (Chan-Palay, 1977). Frequency, size, and GABA uptake, therefore, are three useful criteria for cell identification.

Neurogenesis in the rat cerebellum is spread out over a long period of time, from embryonic day 13 to the 2 nd and even 3rd postnatal weeks (Altman and Bayer, 1978). Most Purkinje cells and neurons of the deep cerebellar nuclei cease to divide on embryonic days 13 to 16 (E13 to 16), while Golgi cells (E19 to postnatal day 2 (PN2)), basket cells (PN5 to 10), stellate cells (PN7 to 12), and granule cells (PN5 to 21) originate at later times (Altman and Bayer, 1978). By making cultures from rats at different stages of neurogenesis, we sought to vary the classes of neurons in the cultures as had been done for stellate cells (Lasher, 1974) and for cultures of the hippocampus (Banker and Cowan, 1977). We analyzed these cultures for neuronal size, GABA uptake, and surface antigens.

The antigens Thy-1.1 and Thy-1.2 are brain and thymus alloantigens, defined by immunization of mice with thymocytes of genetically different mouse strains (Reif and Allen, 1964). The Thy-1.1 antigen is also on rat brain and thymus, has been purified from brain, is a plasma membrane glycoprotein, and has been sequenced (Williams et al., 1977; Campbell et al., 1979). In brain tissue, the antigen is low at birth and increases rapidly during the 2 nd and 3rd weeks of postnatal development to high levels (Reif and Allen, 1964; Douglas, 1972).

Mirsky and Thompson (1975), using embryonic mouse brain cultures, showed that Thy-1 was a surface marker for $30 \%$ of the neurons, whereas glial cells were negative. In the peripheral nervous system, all neurons in cultures of rat dorsal root ganglia were Thy-1 positive, whereas Schwann cells, also of neural crest origin, were negative (Fields et al., 1978). In short term cultures of the rat CNS, oligodendroglia and most astrocytes had no Thy-1 (Raff et al., 1979), although in long tern cultures, many astrocytes became positive (Pruss, 1979). In tissue sections, antigen apparently was expressed by neurons rather than glial cells (Barclay and Hydén, 1978; Barclay, 1979), which is in agreement with positive values for synaptosomes (Stohl and Gonatas, 1977; Acton et al., 1978) and, to some extent, with results using isolated cells (Watanabe et al., 1981). However, in short term rat CNS cultures, nearly all neurons were Thy-1 negative (Currie et al., 1977; Raff et al., 1979). This work is a detailed examination of neuronal Thy-1 expression in cerebellar cultures.

\section{Materials and Methods}

Cell culture. Cell isolation and culture were carried out as previously described (Currie and Dutton, 1980; Dutton et al., 1981). Briefly, cerebella of Wistar rats, varying in age from embryonic day 18 to postnatal day 4, were recovered and the meninges were stripped off and discarded. Chopped, pooled cerebella (150 to $200 \mathrm{mg}$, wet weight) were digested with trypsin and dissociated by trituration in the presence of albumin, trypsin inhibitor, and DNase. Debris was removed by centrifugation through a $4 \%$ albumin solution, and 0.5 to $1.0 \times 10^{6}$ cells were plated onto poly-L-lysine-coated (Yavin and Yavin, 1974) 13-mm glass coverslips in Falcon 3008 multiwell dishes. The medium used was Eagles' minimal essential medium (Gibco-Biocult) plus $10 \%$ fetal calf serum, $1.25 \%$ chick embryo extract (Flow Laboratories, Ltd.) clarified by high speed centrifugation, $0.6 \%$ glucose, $25 \mathrm{mM} \mathrm{KCl}$ (Lasher and Zagon, 1972), and $100 \mu \mathrm{g} / \mathrm{ml}$ of gentamicin. 5-Fluoro-2-deoxyuridine (FUdR; $\left.8 \times 10^{-5} \mathrm{M}\right)$ was added to cultures at 24 or $48 \mathrm{hr}$, and the medium was changed twice per week. Cells were most often used at 4 to 8 days in culture, but neurons survived and were studied after 2,4 , and 8 weeks, although there was a serious progressive loss of neurons.

Immunofluorescence. Immunofluorescence was performed as described by Fields et al. (1978). Thy-1 antigen was detected on unfixed, live cells attached to the glass coverslips. After the second layer reagent (goat antimouse immunoglobulin-rhodamine (Nordic, Tilburg, Netherlands), diluted 1:60), the cells were fixed with acid alcohol. These preparations, if stored at $4{ }^{\circ} \mathrm{C}$, last for years without fading. Mouse anti-Thy-1.1 and Thy-1.2 sera were gifts of Dr. P. Lake (University College, London) and were used at 1:20 dilutions. They were adsorbed as previously described to test for the specificity of staining (Fields et al., 1978) using tissue from AKR mice and rats, which express the Thy-1.1 alloantigen on thymus and brain, and from CBA or AKR/Cumberland mice, which have the Thy-1.2 alloantigen instead.

Rabbit antibody to purified Thy-1 glycoprotein (Barclay et al., 1975) was a gift of Dr. A. Williams (Oxford University) and was used as previously described (Fields et al., 1978).

The specificity and properties of a rabbit antiserum to galactocerebroside have been described previously (Raff et al., 1978); the serum used was made by Dr. M. Raff (University College, London). Rabbit anti-tetanus toxoid (a gift of Dr. R. Mirsky, University College, London) was used to detect the binding of tetanus toxin (a gift of Dr. R. P. Thompson, Wellcome Research Laboratories) as previously described (Fields et al., 1978). Rabbit antiglial fibrillary acidic protein (GFAP) was a gift of Drs. D. Dahl and A. Bignami (Harvard Medical School) and was used on cells prefixed with acid alcohol, or on cells first stained live for Thy-1, and then fixed and stained for GFAP filaments using two contrasting fluorochromes (Raff et al., 1978).

Cells were examined and photographed with a Zeiss standard microscope equipped with epifluorescent illumination, filters selective for rhodamine or fluorescein, and alternate phase contrast illumination. Nearly all of the staining was photographed on Kodak Tri-X or Ektrachrome 400 film using a $\times 63$ objective.

$\gamma$-Aminobutyric acid labeling. $\left[{ }^{3} \mathrm{H}\right] \mathrm{GABA}$ uptake and autoradiography (Lasher, 1974) were performed as previously described (Currie and Dutton, 1980). Briefly, cells 
on coverslips were incubated for 30 to $40 \mathrm{~min}$ at $37^{\circ} \mathrm{C}$ with Earle's salt solution containing $2 \times 10^{-7} \mathrm{M}(10 \mu \mathrm{Ci} /$ ml) $\left[{ }^{3} \mathrm{H}\right] \gamma$-aminobutyric acid $\left({ }^{3} \mathrm{H}\right] \mathrm{GABA}$, Amersham) and $10^{-3.1}$ M $\beta$-alanine (Sigma). The coverslips were rinsed with phosphate-buffered saline (PBS), fixed for $15 \mathrm{~min}$ with $2.5 \%$ glutaraldehyde in PBS, coated with emulsion, and developed after a 10-day exposure at $-20^{\circ} \mathrm{C}$. Omission of $\beta$-alanine resulted in uptake of GABA by nonneuronal flat cells, probably by a glial uptake system (Schon and Kelly, 1975). The neuronal specificity of GABA uptake in the presence of $\beta$-alanine was tested by adding $5 \times 10^{-4} \mathrm{M}$ cis-1,3-aminocyclohexanecarboxylic acid (ACHC, kindly supplied by N. G. Bowery, St. Thomas' Hospital, London), a potent inhibitor of neuronal GABA uptake (Bowery et al., 1976).

The size of immunofluorescent or $\left[{ }^{3} \mathrm{H}\right] \mathrm{GABA}$-labeled cells was evaluated using an eyepiece micrometer. The cell diameter of 50 positive cells was measured in the longest dimension and at a right angle to this. Cells were assigned to one of five size classes according to their average diameter: small $(6.0$ to $8.5 \mu \mathrm{m})$, medium ${ }_{1}(8.6$ to $10.9 \mu \mathrm{m})$, medium $_{2}$ (11.0 to $13.4 \mu \mathrm{m}$ ), large (13.5 to 15.8 $\mu \mathrm{m})$, or very large $(>15.9 \mu \mathrm{m})$. The slides scored in this manner were all prepared at the same time and processed together.

\section{Results}

Cerebellar cell cultures. Embryonic and early postnatal rat cerebellar cells could be cultured for 2 weeks or longer. There was a high proportion of neuronal cells and good visual resolution of many individual neurons. The polylysine substrate, high $\mathrm{KCl}$, and fluorodeoxyuridine (FUdR) were all necessary to obtain adequate neuronal survival with minimal aggregation such that the immunofluorescent staining patterns of individual neurons were distinct. Non-neuronal cells spread out and formed a monolayer, but their proliferation was inhibited by FUdR. Neurons attached and extended processes on the coated glass and on top of the flat cells. During the 2nd week in culture, there was a considerable loss of neurons, and many that did survive were in clusters. There was also extensive aggregation of many neurites into bundles.

In the cultures of postnatal rats, most neurons were small, 6 to $8 \mu \mathrm{m}$ in diameter, and had several processes (Fig. 1A). These cells bound tetanus toxin, in agreement with previous work (Mirsky et al., 1978). In cultures from embryonic animals of 18 to 21 days gestation, there were many large neuronal looking cells 14 to $16 \mu \mathrm{m}$ in diameter in addition to small and intermediate size neurons (Fig. $1 B$ ). The larger cells also bound tetanus toxin (Fig. 1C). The same large cells failed to bind antisera specific for galactocerebroside (GC) or glial fibrillary astrocytic protein (GFAP), markers for oligodendrocytes and astrocytes, respectively (Raff et al., 1979).

Oligodendrocytes were present in the cultures in small numbers, $<2 \%$ of all cells, judging by staining with antiGC serum (Fig. 1, $D$ and $E$ ). The cell bodies of GCpositive cells were 8 to $10 \mu \mathrm{m}$ in diameter and were slightly larger than the abundant small neurons. The orientation of their processes (Fig. $1 D$ ) was very different from that of any of the tetanus toxin-binding cells. For example, the GC-positive processes in Figure $1 \nu$ all belong to a single cell and suggest a fused network rather than the very directional processes characteristic of neurons. Very thin, flat sheets of GC-positive membranes frequently were observed, often combined with processes. In general, GC-positive cells had many processes localized around the cell body rather than a few very thin and very long processes, which were characteristic of neurons with comparable cell somas. Because of the difficulty of tracing complicated processes by phase contrast images alone, antigenic markers such as GC were essential for confident identification of the cells with small, phasebright cell somas and provided the estimate of oligodendroglial cell frequency.

GC-positive cells in these and other CNS cultures failed to bind tetanus toxin and did not express the Thy1 antigen (Raff et al., 1978, 1979). GC-positive cclls were less frequent in embryonic than in postnatal cultures. In this study, some oligodendroglial cells may have been mistaken for neurons when cell soma morphology ("neuronal looking cells") was used in evaluating Thy-1-positive cell frequency. Such cells were $<5 \%$ of the total "neurons" and they were not Thy-1 positive.

Thy-1 antigen on small neurons. During the 1st week in culture, very few of the cerebellar neurons from postnatal rats had detectable Thy-1.1 surface antigen. During the 2nd week, weak staining of some of the small cells was observed. With more time in culture, the antigen density on the neuronal cells increased and the proportion of the neuronal population that was Thy-1.1 positive rose to between 30 and $50 \%$ (Table I). The cell bodies of the positive cells were 6 to $10 \mu \mathrm{m}$ in diameter, were round or slightly oval, and had antigen-positive processes (Fig. 2 ). With the best available alloantisera, it was evident that a high proportion of cells could develop Thy-1 but that positive neurons did not have a uniform amount of antigen and some appeared to have none. With more potent sera, a larger proportion of cells might have been scored as positive.

Thy-1 staining was not continuous and smooth but irregularly distributed. Since the cells were exposed before fixation to two layers of antibody, anti-Thy-1.1, and anti-immunoglobulin, this distribution may reflect crosslinking and induced movement of antigen by the reagents rather than showing the original antigen distribution.

Various control antisera were used to test whether the antigen on cerebellar cells behaved as expected for Thy1.1. It did in that (1) mouse antiserum to Thy-1.2 alloantigen did not bind to cells in the cultures (Fig. 2), (2) the binding antibodies in the mouse anti-Thy-1.1 serum could be absorbed by AKR (Thy-1.1) mouse brain but not by AKR liver, (3) brain tissue from the CBA strain (Thy-1.2) mouse or AKR/Cumberland mouse (a Thy-1.2 inbred AKR strain that differs little from the AKR parent except at the Thy-1 locus) did not absorb the staining antibodies, and (4) rabbit anti-Thy-1 serum bound to the same cell types as mouse anti-Thy-1.1 sera. These controls support the conclusion that the antigen is rat Thy1.

Double antibody staining, using contrasting fluorochromes for the two antigens, showed that the round or oval cells with processes that bound anti-Thy-1 serum also bound tetanus toxin. Many toxin-binding cells and processes had no detectable Thy-1; thus, the Thy-1-positive cells in the cultures were a subset of all of the 

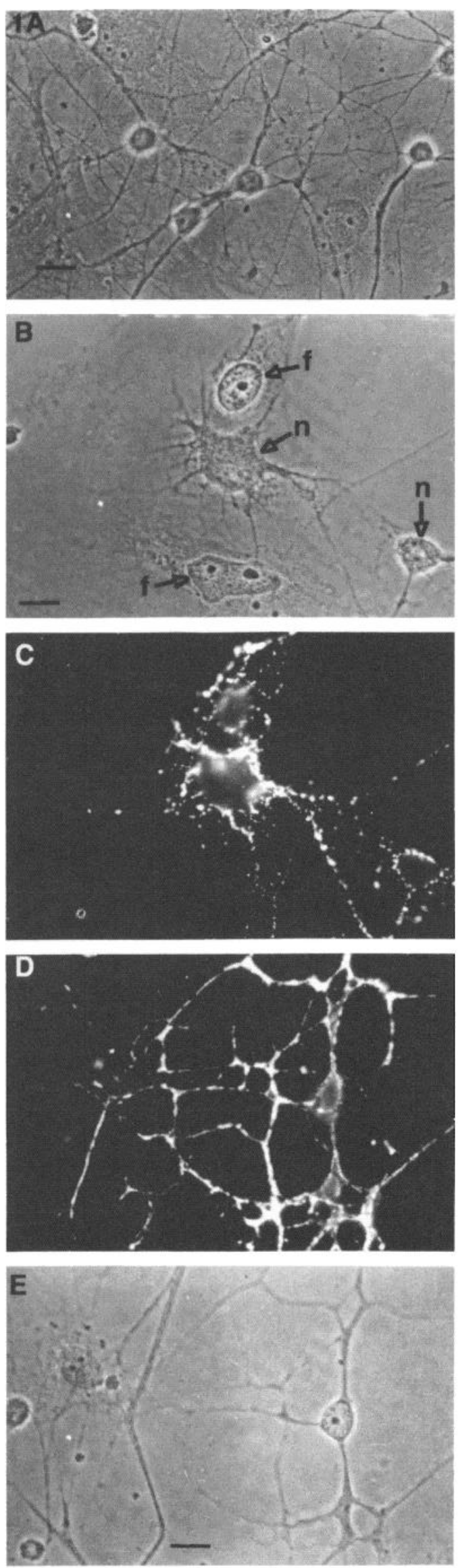

TABLE I

Immunofluorescent staining of small neurons with anti-Thy-1.1 Live cells, maintained in culture for 6 to 60 days, were assayed by indirect immunofluorescence staining for cells expressing surface Thy1.1 antigen.

\begin{tabular}{ccccc}
\hline $\begin{array}{c}\text { Age of } \\
\text { Rat }\end{array}$ & $\begin{array}{c}\text { Days } \\
\text { In Vitro }\end{array}$ & $\begin{array}{c}\text { Total } \\
\text { Neurons }\end{array}$ & $\begin{array}{c}\text { Thy-1.1 } \\
\text { Positive }^{a}\end{array}$ & \begin{tabular}{c} 
Percent Thy-1.1 $_{\text {Positive }^{a}}$ \\
\hline days
\end{tabular} \\
2 & 6 & 574 & & \% \\
2 & 20 & 406 & 54 & 0.2 \\
2 & 35 & 204 & 76 & 13 \\
2 & 43 & 158 & 78 & 37 \\
2 & 60 & 161 & 67 & 49 \\
Fetal & 30 & 161 & 64 & 42 \\
\hline
\end{tabular}

"Strongly stained positive neurons.

neurons (Fig. $2 B$ ). None of the flat cells bound tetanus toxin, in agreement with previous reports (Mirsky et al., 1978; Raff et al., 1979; Currie and Dutton, 1980).

Double antibody staining with rabbit anti-GFAP serum and mouse anti-Thy-1.1 showed that none of the Thy-1-positive cells that were scored as neurons on the basis of their morphology had GFAP, an antigen related to astrocytic filaments. Most of the flat background cells, however, were GFAP positive.

Thy-1.1 on neurons in embryonic cerebellar cultures. Large neurons, rare in cultures of 2- to 5-day-postnatal cerebellum, were common in cultures of embryonic rats. Thy-1.1 antigen-positive cells with asymmetric, large perikarya 10 to $20 \mu \mathrm{m}$ in diameter were also frequent (Fig. 3). They usually had multiple processes, some of which were very long. Such positive cells were detected at 3 to 10 days in vitro, whereas they were stained weakly at earlier times. They were present in cultures from embryonic rats (E18 to 21), variably demonstrated in newborn rats, and not found in cultures from rats older than 2 days (Table II).

The highest value for Thy-1.1-positive cells in any of the cultures was $47 \%$ of all neurons in cultures from 25 mm (E19) embryos (Table II). Although the Thy-1-positive cells could not be picked out reliably by morphology

Figure 1. Morphology of neurons and oligodendrocytes in cerebellar cultures. $A$, Typical small neurons from 1-day-old rats, 8 days in culture, fixed with acid alcohol. Cells were 6 to $8 \mu \mathrm{m}$ in diameter, developed a network of processes, and grew upon a layer of large flat cells. $B$ and $C$, Two neuron-like cells of different sizes from rats of embryonic day 19 at 8 days in culture. The cells were incubated with tetanus toxin $(10 \mu \mathrm{g} / \mathrm{ml})$ antitoxoid (1:50) and goat anti-immunoglobulin-rhodamine (1:100), fixed with acid alcohol, and viewed with phase contrast optics $(B)$ or by UV illumination and filters for rhodamine fluorescence $(C)$. Flat fibroblastic or glial cells (marked $f$ ) did not bind toxin, but both rounded, neuronal looking cells (marked $n$ ) had toxin receptors. $D$ and $E$, Cerebellar cells from 3 -day-old rats, 6 days in culture were stained with rabbit antigalactocerebroside $(1: 50)$ to detect differentiated oligodendrocytes. The same field, containing 1 positive cell, was photographed to show immunofluorescence $(D)$ or the phase contrast image $(E)$. Note that the flat cell, the neuronal cell bodies, and the bundle of neuronal processes (traversing from top to bottom of the field) were not stained. Magnification $\times 608$; bars, $10 \mu \mathrm{m}$. 

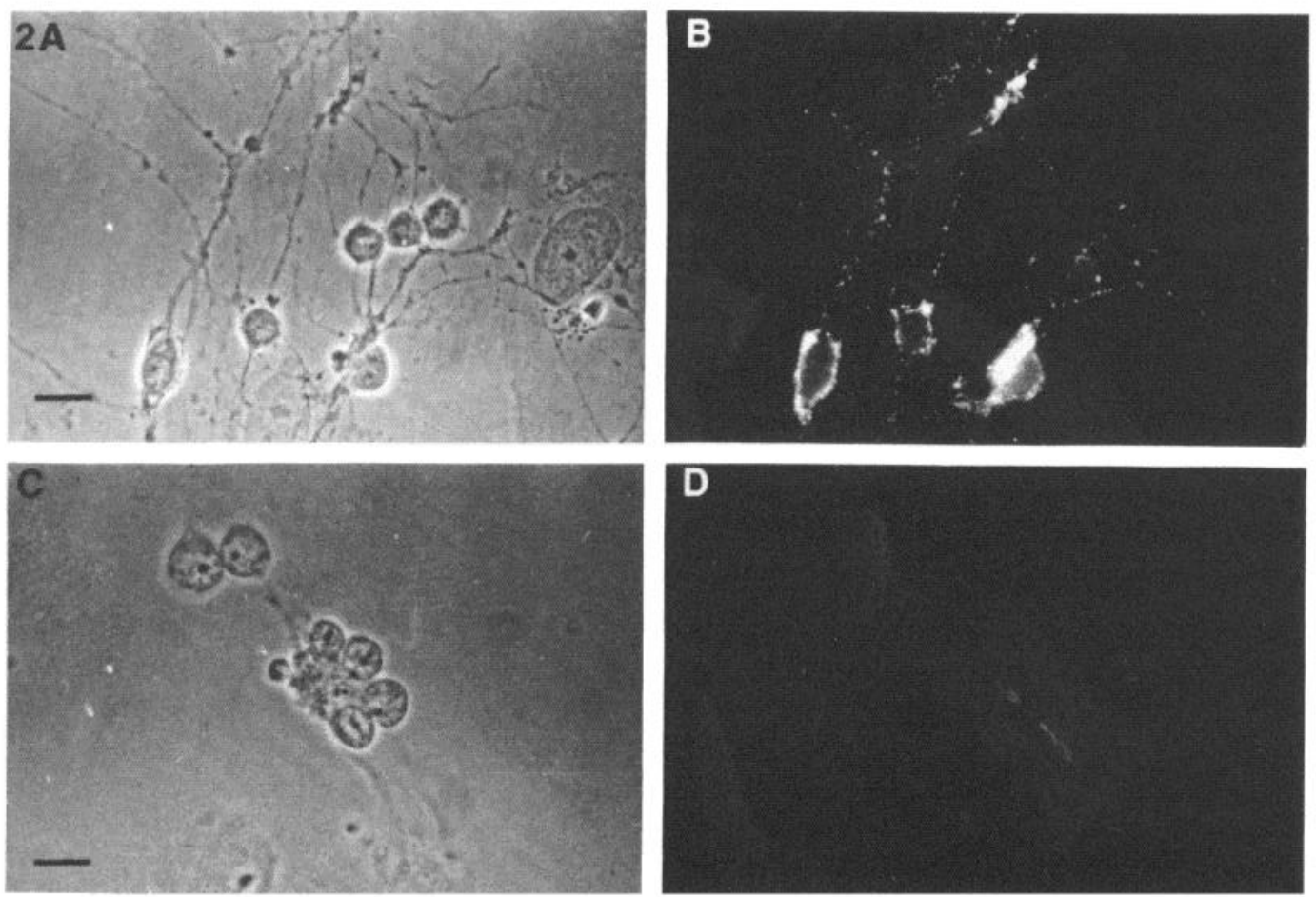

Figure 2. Small cerebellar neurons from newborn rats become Thy-1.1 positive in culture. These cells were in culture 35 days and stained with mouse anti-Thy-1.1 or mouse anti-Thy-1.2 (diluted 1:20) and goat anti-mouse immunoglobulin-rhodamine (1:60). A, Phase contrast micrograph. Note 6 neurons and 2 flat cells. $B$, Fluorescence after incubation with anti-Thy-1.1. Three of the neurons and their processes were positive; the other 3 and the flat cells were negative. $C$ and $D$, Cells on a parallel coverslip were incubated with mouse anti-Thy-1.2 (1:20) and photographed using phase contrast $(C)$ or fluorescence optics $(D)$. No surface binding was detectable and the background was low. Processing of this photograph $(D)$ was parallel to $B$. Magnification $\times 608$; bars, $10 \mu \mathrm{m}$.

alone, nearly all of the small neurons were negative and nearly all of the larger neurons were positive (Fig. 4). After 10 days in culture, the large neurons died off, although some may have survived in the aggregates of neurons which form after 10 to 14 days.

Specificity controls with anti-Thy-1.2 and absorbed sera as described above were done on embryonic and newborn rat cultures containing the large, positive cells. In all respects, the results were consistent with the staining of the cells by antibodies specific for Thy-1.1.

Double antibody labeling for Thy-1.1 antigen and tetanus toxin binding showed that the large Thy-1-positive cells had toxin receptors but that many toxin-binding cells, especially the small ones, were Thy-1 negative. In addition, double staining for GFAP showed that the Thy1.1-positive cells in embryonic rat cultures lacked GFAP filaments (none positive out of 20 cells) and were therefore unlikely to be astrocytes or the anomalous GFAPpositive, weakly tetanus toxin-binding cells found in optic nerve cultures by Raff et al. (1979).

$\gamma$-Aminobutyric acid (GABA) uptake. Glial cells have a high affinity GABA uptake mechanism that can be blocked by the competitive inhibitor, $\beta$-alanine (Schon and Kelly, 1975). Some neurons, probably only those that use GABA as a neurotransmitter, have a separate GABA uptake mechanism which is not inhibited by $\beta$-alanine. In our postnatal cerebellum cultures incubated with $\left[{ }^{3} \mathrm{H}\right]$
GABA in the presence of $1 \mathrm{~mm} \beta$-alanine, more than $90 \%$ of the small neurons failed to show any GABA uptake. This agrees with previous studies (Lasher, 1974) and is consistent with their being granule cell neurons. There were $\left[{ }^{3} \mathrm{H}\right] \mathrm{GABA}$-positive cells in cultures from all rat ages tested. Their GABA uptake was insensitive to $\beta$ alanine but was eliminated by aminocyclohexanecarboxylic acid (ACHC), an indication that they were probably all neurons (Bowery et al., 1976).

The frequency and morphology of the $\left[{ }^{3} \mathrm{H}\right]$ GABA-labeled cells varied with the age of the rat. The frequency of GABA-positive cells was highest in cultures from embryonic rats, intermediate in cultures from newborn rats, and lowest from 4-day-old animals (Table II): in all, there was a 7 -fold decrease with increasing age. In the same cultures, Thy-1-positive neurons also varied, but the decrease was 50 -fold (Table II). Also, the frequency of Thy-1-positive neurons changed as small neurons became positive at longer times in culture.

The GABA-positive and Thy-1-positive neurons in 1week-old cultures of embryonic rats were morphologically similar. Large, multipolar positive cells were prominent with both labels (Figs. 3 and 5). A very few of the small cells were Thy-1 positive (Fig. $3 H$ ). They had weak Thy-1 fluorescence and were noticed only in postnatal rat cultures.

To quantitate the morphological similarity, the size 

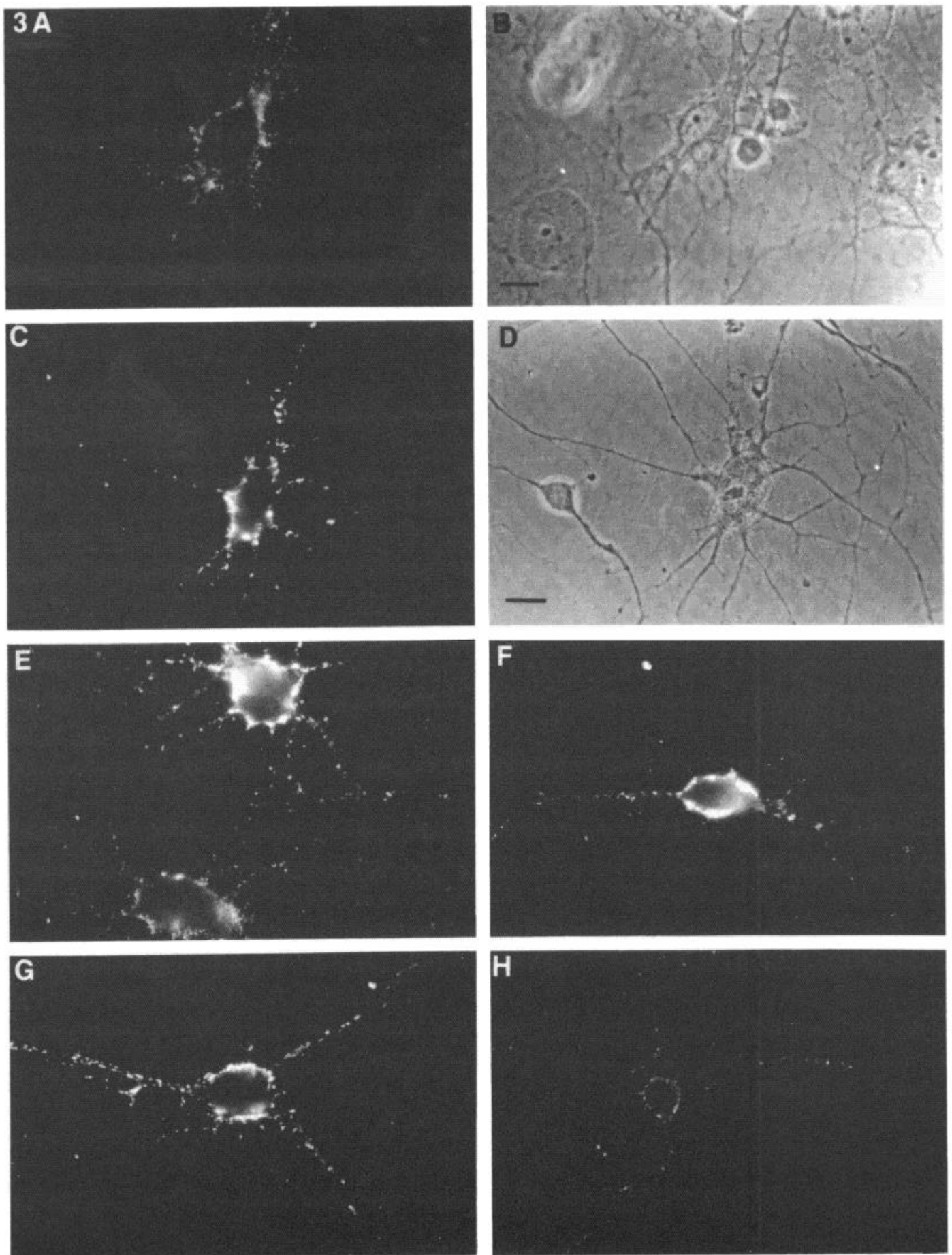

Figure 3. Thy-1.1-positive neurons among cultured embryonic cerebellar cells. These cells were from E19 rats, cultured 8 days, and stained with mouse anti-Thy-1.1 serum. $A, C$, and $E$ to $G$ show fluorescence due to antigen on the membrane of the cell body and processes of individual cells. $B$, Phase contrast micrograph of the same field as in $A$. Note that the small cells did not stain. $D$, Phase contrast micrograph of the same field as in $C$. Note the small neuron that did not stain, typical of all 6- to $8-\mu \mathrm{m}$ neurons in these cultures. Most positive neurons were multipolar ( $A$ to $E$ ), but some had fewer processes $(F$ and $G$ ). In comparison, cultures of PN1 rats resulted in few Thy-1.1-positive cells at 8 days in culture. Their positive cells $(H)$ were usually small and had weaker binding than embryonic positive cells. Magnification $\times 608$; bars, $10 \mu \mathrm{m}$.

distributions of the Thy-1-positive neuronal looking cells and the GABA-positive cells were evaluated for small samples of positive cells (Fig. 6). Thy-1-stained cultures were fixed after antibody binding with acid alcohol, whereas GABA-labeled cell cultures were fixed with glutaraldehyde. An undesirable effect of alcohol fixation was an increase in the diameter of neurons by about $5 \%$, and we have applied a correction for this effect. A direct 


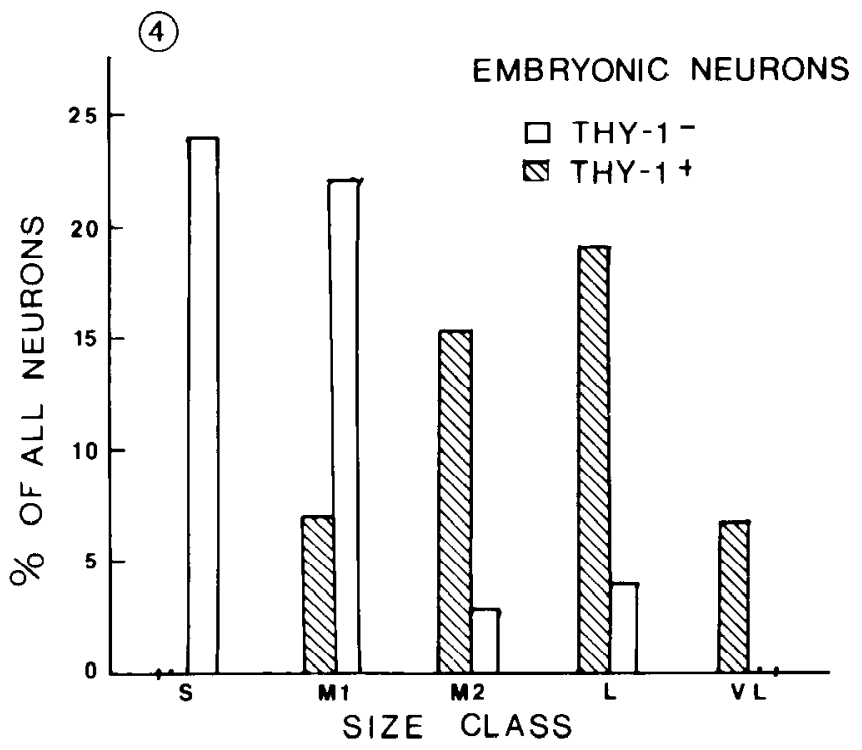

Figure 4. Size distribution of embryonic neurons positive or negative for Thy-1. Cerebellar cells from E19 embryonic rats $(25 \mathrm{~mm})$ were cultured for 8 days and tested for 'I'hy-1.1 using indirect immunofluorescence. Neuron-like cells with round cell bodies and processes ( 105 cells) were scored as Thy-1 positive (50) or negative (55) and the cell soma average diameter was measured. Size classes were established $\left(S=6\right.$ to $8.5 \mu \mathrm{m} ; M_{1}$ $=8.6$ to $10.9 \mu \mathrm{m} ; M_{2}=11$ to $13.4 \mu \mathrm{m} ; L=13.5$ to $15.8 \mu \mathrm{m} ; V L$ $=\geq 15.9 \mu \mathrm{m})$ and the size distribution of Thy-1-positive (hatched bars) and Thy-1-negative (open bars) neuron-like cells is shown.

comparison of Figure $6, A$ and $B$ must be made with some reservations. However, the information obtained by measuring the cells was sufficient to establish several points. (1) There was more than one population of Thy1-positive cells. Most Thy-1-positive cells in cultures of embryonic rats were significantly larger than the Thy-1positive cells from 1-day-old rats (Fig. 6A). The large Thy-1-positive cells ( $L$ and $V L$ classes; diameter, $\geq 13.5$ $\mu \mathrm{m}$ ) were 20 - to 50 -fold more frequent in embryonic than in 1-day rat cultures (data from Table II and Fig. 6A). The smallest Thy-1-positive cells ( $S$ class, 6 to $8.5 \mu \mathrm{m}$ ) were not observed in embryonic cultures and represented about $1 \%$ of all of the neurons in 1-day rat cultures. (2) There was more than one population of GABA-positive cells. The size distributions of GABA-positive cells in 1 - and 4-day rat cultures were similar but quite different from the distribution in embryonic cultures (Fig. 6B). There was a large overlap of the distributions, but the smallest GABA-positive cells were seen in postnatal cultures, and the large positive cells were 10-fold more common in embryonic cultures than in 1-day rat cultures (Table II; Fig. 6B). (3) Most large embryonic neurons were Thy-1 and GABA positive. The size distributions of Thy-1-positive and GABA-positive cells in embryonic cultures were quite similar and together with the size distribution of all of the cells (Fig. 4) rule out any possibility that the Thy-1- and GABA-positive cells were entirely different cells. There were not enough Thy-1negative large and medium size neurons to allow a significant Thy-1-negative, GABA-positive population (Fig. 4). However, such cells could be present among the small and medium size classes in embryonic cultures and certainly were present in the postnatal cultures, since they had many more GABA-positive than Thy-1-positive cells (Table II). (4) Small GABA-positive cells and small Thy1-positive cells were present in the postnatal cultures but were minor subpopulations at 1 week in vitro, even though small cells ( 6 to $8.5 \mu \mathrm{m}$ ) were very common in all cultures.

Thy-1-positive fibroblasts and astrocytes. In addition to the neurons, some non-neuronal cells were positive for 'Thy-1.1 in all cultures. They were flat, irregularly shaped, and often became very large. In eight experiments, an average of $8 \%$ of all cells were flat and Thy-1.1 positive (range, 3 to $12 \%$ ). Tissue adsorptions that remove the staining of the neurons also removed the flat cell staining. As described more fully elsewhere (Raff et al., 1979), most of these cells were labeled with anti-fibronectin and were indistinguishable from fibroblasts.

Using double antibody staining with anti-GFAP as a positive marker for astrocytes, we found that only $3 \%$ of the GFAP-positive flat cells expressed Thy-1.1 during the 1 st week in vitro. At 35 days in vilro, $7 \%$ of all the GFAP-positive cells were Thy-1 positive. Even at this time, most of the background cells were positive only for GFAP $(80 \%)$ or only for Thy-1 (3\%). Pruss (1979) had found many more astrocytes to be double labeled. Evidently, these culture conditions, while permissive of neuronal Thy-1 development, are not optimal for astrocyte Thy-1.

\section{Discussion}

The cerebellum was chosen for this study because there is good survival of granule cells in dissociated cultures, and other types of cortical neurons can be recognized in cultures by using $\left[{ }^{3} \mathrm{H}\right] \mathrm{GABA}$ uptake and autoradiography. By combining these techniques with immunofluorescence for Thy-1 antigen, we conclude that Thy- 1 is expressed by many small granule neurons after 2 to 4 weeks in culture and by medium and large size

TABLE II

Thy-I antigen and [ $H]$ GABA uptake by neurons from rats of different ages

Cultures were prepared on 1 day from three different age rat litters. At 8 days in culture, parallel coverslips were stained for Thy- 1.1 antigen or were incubated with $\left[{ }^{:} \mathrm{H}\right] \mathrm{GABA}$ in the presence of $1 \mathrm{~mm} \beta$-alanine, fixed, and processed for autoradiography. Between 400 and 600 cells were examined on each coverslip and the percentage of all of the neurons, judged by morphological criteria using phase contrast optics, that were positive for Thy-1 antigen or for GABA uplake was calculated.

\begin{tabular}{|c|c|c|c|c|}
\hline \multirow{3}{*}{ Age of Rat } & \multicolumn{4}{|c|}{ Percent of All Neurons" Positive for } \\
\hline & \multirow{2}{*}{$\begin{array}{c}{\left[{ }^{3} \text { H]GABA }\right.} \\
\text { Uplake }\end{array}$} & \multicolumn{3}{|c|}{ Thy-l Antigen } \\
\hline & & Strong & Weak & Total \\
\hline & & $\because$ & & \\
\hline $\begin{array}{l}\text { Embryonic } \\
\quad(\text { E19; } 25 \mathrm{~mm})\end{array}$ & 41 & 37 & 10 & 47 \\
\hline PNI & 9 & 0.3 & 3.2 & 3.5 \\
\hline PN4 & 6 & 0.0 & $1.0^{\prime \prime}$ & 1.0 \\
\hline
\end{tabular}

"Between 37 and $64 \%$ of all of the cells were neurons in a series of four similar experiments.

"Ten neurons out of 1000 . 

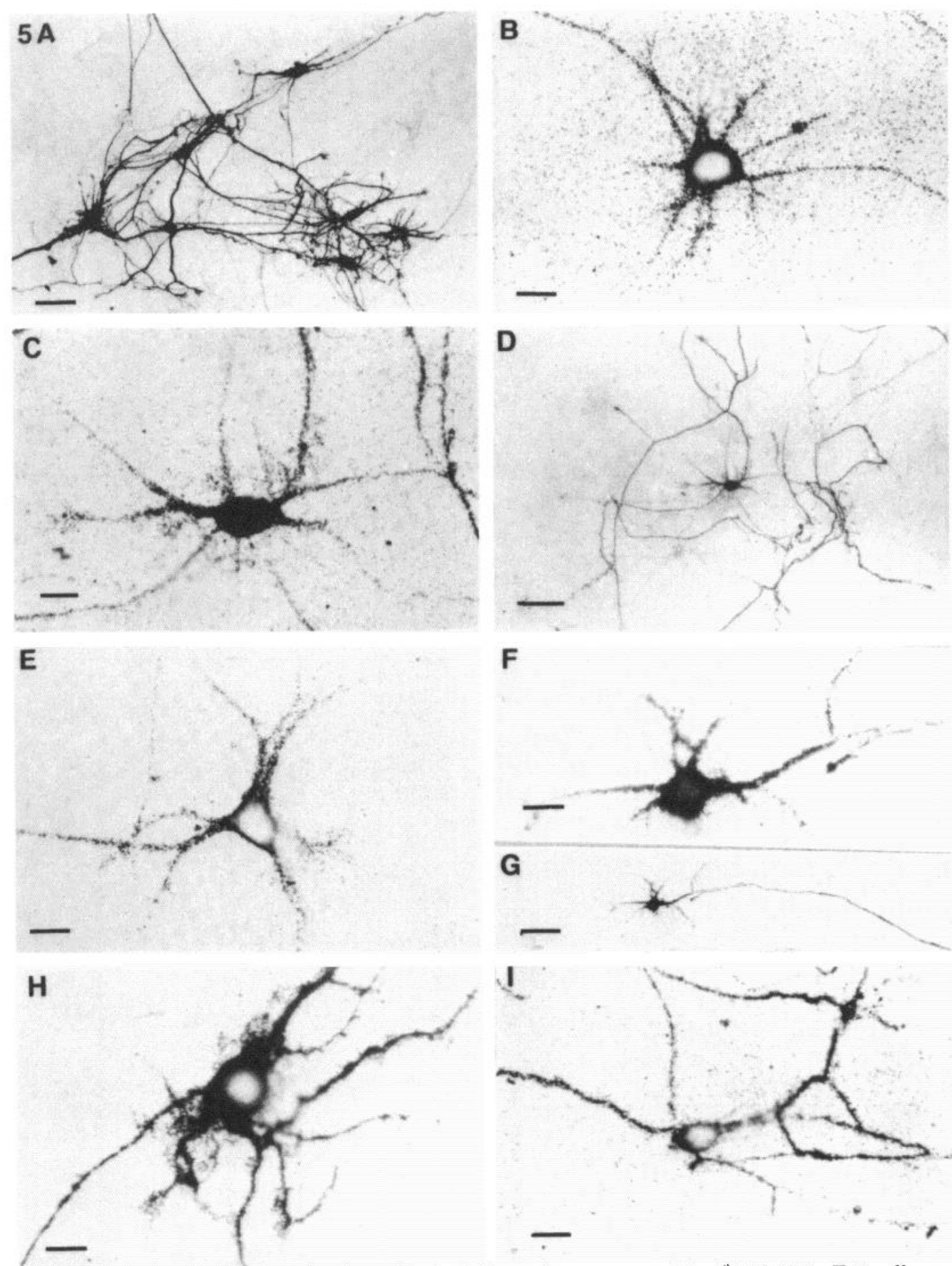

Figure 5. Autoradiography of embryonic cerebellar cultures exposed to $\left[{ }^{3} \mathrm{H}\right] \mathrm{GABA}$. E19 cells were in culture 8 days and were incubated briefly with $\left[{ }^{3} \mathrm{H}\right] \mathrm{GABA}$ plus $1 \mathrm{~mm} \beta$-alanine. Autoradiographs showed that large cells with processes were labeled and were common in these cultures, whereas the non-neuronal cells were unlabeled as were many small neurons. Bright-field illumination showed only the ${ }^{3}$ H-labeled cells. $A$, A region with 8 positive cells. $D$ and $G$, Regions with only 1 labeled cell. Individual cells $(B, C, E$, and $H)$ are often multipolar with long processes $(C$ and $D ; F$ and $G$ ). Positive cells with cell diameters of 6 to $10 \mu \mathrm{m}$ were rare in embryonic cultures $(I)$ but were noticed in cultures from older animals. Lower magnification $(A, D$, and $G) \times 155$; bars, $40 \mu \mathrm{m}$. Higher magnification $(B$, $C, E, F, H$, and $I$ ) $\times 608$; bars, $10 \mu \mathrm{m}$.

neurons after a few days or 1 week in culture. The largest neurons are Thy-1 and GABA uptake positive, are recovered best from embryonic cerebellum before the birth dates of stellate, basket, or most Golgi cells, and are therefore likely to be Purkinje neurons.
Slow development of Thy-1 on granule neurons. The recovery and survival in culture of granule cells have been well documented, including their inability to take up [ ${ }^{3}$ H] GABA (Lasher, 1974; Messer, 1977; Currie and Dutton, 1980). In this study, the granule cells failed to 

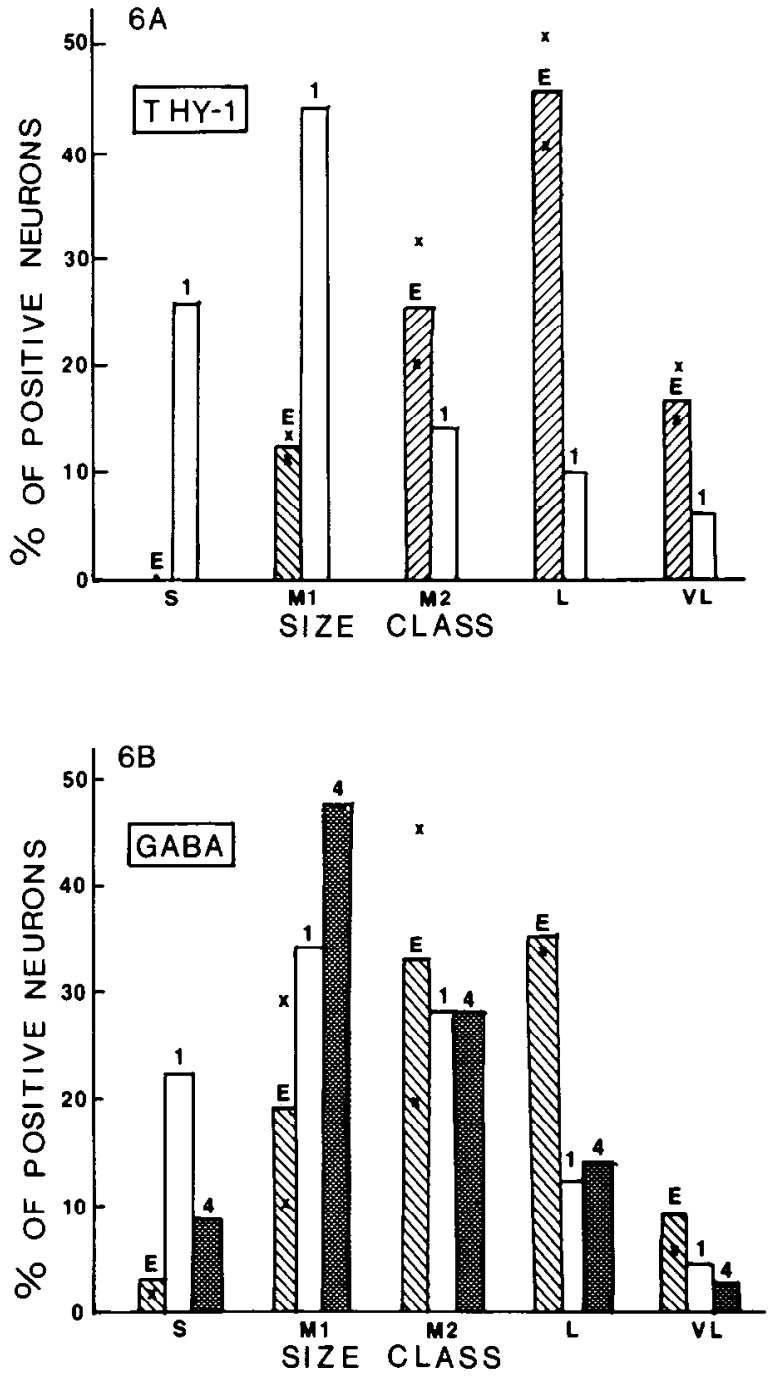

Figure 6. The size of Thy-1 antigen-positive neurons and $\left[{ }^{3} \mathrm{H}\right] \mathrm{GABA}$ uptake-positive neurons in cultures from rats of different ages. Cerebellar cells from embryonic (E19), 1-day-, and 4-day-old rats were in culture for 8 days and then were stained for Thy-1.1 immunofluorescence (Figs. 3 and 4) or exposed to [ $\left.{ }^{3} \mathrm{H}\right]$ GABA (Fig. 5). The percentage of each group of 50 positive neurons with an average cell diameter corresponding to five cell classes- $S, M_{1}, M_{2}, L$, and $V L$ (see the legend to Fig. 4 for micrometer values) -is expressed for cultures from embryonic ( $E$, hatched bars), PN1 (1, open bars), and PN4 (4, cross-hatched bars) rats. Thy-1.1-positive cells $(A)$ and GABApositive cells $(B)$ were measured. Duplicate sets of E19 cultures were analyzed $(X)$. The bars show the average values. The cultures from 4-day-old rats had too few Thy-1-positive neurons to evaluate.

express Thy-1 antigen during the 1st week in culture, but there was a slow increase in expression thereafter until, at 4 weeks in culture, approximately $50 \%$ of the surviving neurons were Thy-1 positive. A few neurons in the postnatal cultures were Thy-1 positive at 8 days in vitro, but their scarcity and their decrease with increasing age of the rat (4\% in 1 day; $1 \%$ in 4 days) make it unlikely that these are granule cells. They could be any of the other smaller neurons of the cerebellar cortex or deep cerebellar nuclei.

The slow increase in antigen-positive cells over 4 weeks in culture is similar to the development of Thy-1 antigen in brain tissue in vivo (Douglas, 1972) and to the antigen increase in re-aggregate cultures in vitro (Zwerner et al., 1977). In dissociated cultures, we proved that the antigen develops on the neuronal membranes and assessed the contribution of the non-neuronal cells. Since fibroblasts (Stern, 1973) and some astrocytes (Pruss, 1979) are Thy1 positive, the average culture values may not indicate neuronal differentiation. The increase in positive neurons occurs in the absence of myelination and perhaps without all of the differentiation that occurs in aggregate cultures (Seeds, 1973; Trenkner and Sidman, 1977). The antigen is expressed equally on membranes of the cell soma and processes. We could not observe any visible concentration at sites likely to be synapses. While Thy-1 antigen has been found on synaptosomes, it may not be concentrated at the synapse preferentially (Acton et al., 1978; Stohl and Gonatas, 1977).

An immunofluorescence study of the distribution and development of Thy-1 in rat brain (Barclay and Hydén, 1978; Barclay, 1979) concluded that Thy-1 was present in the granular and molecular layers, the sites of the cell bodies and processes of granule cells. Furthermore, a gradual increase in antigen was seen in the tissue sections over the first weeks of age. Our work with cultures proves that the antigen is clearly on neuronal membranes, which was difficult to show in tissue sections, and thus agrees with positive staining of dissected adult neurons (Barclay and Hydén, 1979).

Even after 4 weeks in culture, there were many cerebellar neurons that did not stain for Thy-1 (Fig. 2). Mirsky and Thompson (1975) also found that $70 \%$ of their mouse CNS neurons appeared negative for the mouse Thy- 1 antigen. This also may be true in vivo or may indicate a failure of the cells to differentiate completely or form synaptic connections in vitro. All dorsal root ganglion neurons, in contrast, were antigen positive (Fields et al., 1978), and in the embryonic cerebellum cultures, nearly all of the neurons of the two largest size classes were 'l'hy-1 positive. Thus, there may be unidentified aspects of neuronal differentiation for which the appearance of Thy-1 antigen is a useful index.

Neurons from embryonic tissue with Thy-1 antigen. Large, usually multipolar Thy-1-positive neurons were found in the cultures of embryonic cerebellum. Unlike granule cells, they developed Thy-1 antigen within a few days in culture. They are likely to include significant numbers of Purkinje cells for the following reasons. (1) There were no Thy-1-negative cells among the largest neurons (Fig. 4). (2) There were many GABA-positive cells in the cultures, especially among the largest, Thy-1positive cells. High affinity GABA uptake is consistent with the large cells being Purkinje or Golgi cells, for these cells use GABA as their neurotransmitter, as established by a variety of electrophysiological, immunohistochemical, and pharmacological evidence in vivo and in cultures (Obata et al., 1967; Sotelo et al., 1972; McLaughlin et al., 1974). Many deep cerebellar neurons are large, but they are at least 30-fold less numerous than Purkinje cells, do not take up GABA in vivo (Chan-Palay, 1977), do not label with anti-glutamate decarboxylase antibodies (McLaughlin et al., 1974), and therefore are unlikely to be the Thy-1-positive, GABA-positive large neurons. (3) E19 embryonic cultures had the highest frequency of 
large Thy-1-positive cells. Golgi cell neurogenesis in the rat is delayed substantially compared to that of Purkinje cells. Most Golgi cells divide until days E18 to PN2 (Altman and Bayer, 1978). According to Banker and Cowan (1977), dividing hippocampal neurons are not recovered efficiently in dissociated cell cultures. If their results apply equally to cerebellum, good recovery of Purkinje cells, but not Golgi cells, might he expected from E19 tissue. Thus, the better recovery from embryonic rather than neonatal tissue of large Thy-1 cells suggests that they are not Golgi neurons. (4) Basket, stellate, and granule cells of cerebellar cortex are largely postnatal in origin (Altman, 1970); therefore, none of them would be expected to be preferentially recovered from embryonic tissue. Stellate and basket cells, identified by light and electron microscopy in postnatal rat cultures (Lasher, 1974; Burry and Lasher, 1978), have smaller cell diameters $(\sim 10 \mu \mathrm{m})$ than the Thy-1-positive and/or GABA-positive cells in the three larger cell classes (all $\geq 11 \mu \mathrm{m}$ ) that dominate the embryonic positive cell populations (Fig. 6). (5) Large neurons from postnatal cerebellum, dissociated and separated from smaller cells by sedimentation, have the ultrastructural characteristics of Purkinje cells (Cohen et al., 1978). Such large cells after $20 \mathrm{hr}$ in culture are Thy-1 positive and bind tetanus toxin (J. Cohen and K. L. Fields, unpublished observations), but they do not survive much longer in culture. It would appear possible that their survival is better when they are isolated from less mature embryonic cerebellum. (6) The presence of multiple perisomatic dendrites on Thy-1-positive large embryonic cells is similar to the morphology of Golgi-stained immature mouse Purkinje cells in vivo and cells in mouse explant cultures identified by light and electron microscopy as Purkinje cells (Hendelman and Aggerwal, 1980; Aggerwal and Hendelman, 1980).

Morphological and cytochemical maturation. Perisomatic dendrites are not characteristic of adult Purkinje cells, but an arrest of morphological maturation at a stage corresponding to the early postnatal period in vivo would be expected from work with mouse explant cultures (Hendelman and Aggerwal, 1980). In vivo, the pattern of dendritic development is dependent upon the correct cortical environment. Some Purkinje cells maintain a multipolar structure when the cerebellar cortex is depleted of granule cells by irradiation (Berry and Bradley, 1976) or in the reeler mutant (Caviness and Rakic, 1978). One of the reasons for identification and separation of cell classes is to recombine them in a controlled manner. By adding postnatal granule cells to embryonic cultures, we may test whether the large cells mature further or remain viable in culture for longer periods. Pervasive neuronal death in these dissociated cultures is one of the most serious limitations of this technique.

So far, Thy-1 appears to be a unique surface antigen for it discriminates among cerebellar neurons in culture. Other membrane antigens, defined recently by monoclonal antisera, are present on cerebellar neurons but apparently on them all (Cohen and Selvendran, 1981; Hogg et al., 1981; Hirn et al., 1981). Retinal neuron markers (Eisenbarth et al., 1979; Barnstable, 1980), which differentiate between layers in tissue sections, have not been analyzed in cerebellar cultures. Neuron-specific enolase, an antigenic cytoplasmic enzyme, is similar to Thy-1, since it can be used to evaluate neuronal differentiation in culture (Schengrund and Marangos, 1980). Reports of specific Purkinje cell staining for cytoplasmic antigens (Woodhams et al., 1980; Lohmann et al., 1981; ChanPalay et al., 1981; Nilaver et al., 1982) suggest that further immunocytochemical tests are an appropriate approach to test our conclusion that Purkinje cells are prominent among the Thy-1-positive neurons.

\section{References}

Acton, R. T., J. Addis, G. F. Carl, L. D. McClain, and W. F. Bridgers (1978) Association of Thy-1 differentiation alloantigen with synaptic complexes isolated from mouse brain. Proc. Natl. Acad. Sci. U. S. A. 75: 3283-3287.

Aggerwal, A. S., and W. J. Hendelman (1980) The Purkinje neuron: II. Electron microscopic analysis of the mature Purkinje neuron in organotypic culture. J. Comp. Neurol. 193: 1081-1096.

Altman, J. (1970) Postnatal neurogenesis and the problem of neuronal plasticity. In Developmental Neurobiology, W. A. Himwich, ed., pp. 197-237, Charles C Thomas, Springfield, IL.

Altman, J., and S. A. Bayer (1978) Prenatal development of the cerebellar system in the rat. I. Cytogenesis and histogenesis of the deep nuclei and the cortex of the cerebellum. J. Comp. Neurol. 179: 23-48.

Banker, G. A., and W. M. Cowan (1977) Rat hippocampal neurons in dispersed cell culture. Brain Res. 126: 397-425.

Barclay, A. N. (1979) Localization of the Thy-I antigen in the cerebellar cortex of rat brain by immunofluorescence during postnatal development. J. Neurochem. 32: 1249-1257.

Barclay, A. N., and H. Hydén (1978) Localization of the Thy-1 antigen in rat brain and spinal cord by immunofluorescence. J. Neurochem. 31: 1375-1391.

Barclay, A. N., and H. Hydén (1979) Localization of the Thy-1 antigen by immunofluorescence on neurons isolated from rat brain. J. Neurochem. 32: 1583-1586.

Barclay, A. N., M. Letarte-Muirhead, and A. F. Williams (1975) Purification of the Thy- 1 molecule from rat brain. Biochem. J. 151: 699-706.

Barnstable, C. J. (1980) Monoclonal antibodies which recognize different cell types in rat retina. Nature 286: 231-235.

Berry, M., and P. Bradley (1976) The growth of dendritic trees of Purkinje cells in irradiated agranular cerebellar cortex. Brain Res. 116: 361-387.

Bowery, N. G., G. P. Jones, and M. J. Neal (1976) Selective inhibition of neuronal GABA uptake by cis-1,3-aminocyclohexanecarboxylic acid. Nature 264: 281-284.

Burry, R. W., and R. S. Lasher (1978) Electron microscopic autoradiography of the uptake of $\left[{ }^{3} \mathrm{H}\right] \mathrm{GABA}$ in dispersed cell cultures of rat cerebellum. II. The development of GABAergic synapses. Brain Res. 151: 19-29.

Campbell, D. G., A. F. Williams, P. M. Bayley, and K. B. M Reid (1979) Structural similarities between Thy-1 antigen from rat brain and immunoglobulin. Nature 282: 341-342.

Caviness, V. S., and P. Rakic (1978) Mechanisms of cortical development: A view from mutations in mice. Annu. Rev. Neurosci. 1: 297-326.

Chan-Palay, V. (1977) Cerebellar Dentate Nucleus, Organization, Cytology and Transmitters, pp. 17-18, 140-144, Springer, Berlin.

Chan-Palay, V., G. Nilaver, S. L. Palay, M. C. Beinfeld, E. A. Zimmerman, J. -Y. Wu, and T. L. O'Donohue (1981) Chemical heterogeneity in cerebellar Purkinje cells: Existence and coexistence of glutamic acid decarboxylase-like and motilin- 
like immunoreactivities. Proc. Natl. Acad. Sci. U. S. A. 78: 7787-7791.

Cohen, J., and S. Y. Selvendran (1981) A neuronal cell-surface antigen is found in the CNS but not in peripheral neurones. Nature 291: 421-423.

Cohen, J., R. Balázs, F. Hajos, D. N. Currie, and G. R. Dutton (1978) Separation of cell types from the developing cerebellum. Brain Res. 148: 313-331.

Currie, D. N., and G. R. Dutton (1980) [ $\left.{ }^{3} \mathrm{H}\right]$ GABA uptake as a marker for cell type in primary cultures of cerebellum and olfactory bulb. Brain Res. 199: 473-481.

Currie, D. N., K. L. Fields, and G. R. Dutton (1977) GABA autoradiography and Thy-1.1 immunofluorescence properties of primary cell cultures of postnatal rat cerebellum. Proc. Int. Soc. Neurochem. 6: 635 .

Douglas, T. C. (1972) Occurrence of a theta-like antigen in rats. J. Exp. Med. 136: 1054-1062.

Dutton, G. R., D. N. Currie, and K. Tear (1981) An improved method for the bulk isolation of viable perikarya from postnatal cerebellum. J. Neurosci. Methods 3: 421-427.

Eisenbarth, G. S., F. S. Walsh, and M. Nirenberg (1979) Monoclonal antibody to a plasma membrane antigen of neurons. Proc. Natl. Acad. Sci. U. S. A. 76: 4913-4917.

Fields, K. L., J. P. Brockes, R. Mirsky, and L. M. B. Wendon (1978) Cell surface markers for distinguishing different types of rat dorsal root ganglion cells in culture. Cell 14: 43-51.

Hendelman, W. J., and A. S. Aggerwal (1980) The Purkinje neuron: I. A Golgi study of its development in the mouse and in culture. J. Comp. Neurol. 193: 1063-1079.

Hirn, M., M. Pierres, H. Deagostini-Bazin, M. Hirsch, and C. Goridis (1981) Monoclonal antibody against cell surface glycoprotein of neurons. Brain Res. 214: 433-439.

Hogg, N., M. Slusarenko, J. Cohen, and J. Reiser (1981) Monoclonal antibody with specificity for monocytes and neurons. Cell 24: 875-884.

Lasher, R. S. (1974) The uptake of $\left[{ }^{3} \mathrm{H}\right] \mathrm{GABA}$ and differentiation of stellate neurons in cultures of dissociated newborn rat cerebellum. Brain Res. 69: 235-254.

Lasher, R. S., and I. S. Zagon (1972) The effect of potassium on neuronal differentiation in cultures of dissociated newborn rat cerebellum. Brain Res. 41: 482-488.

Lohmann, S. M., U. Walter, P. E. Miller, P. Greengard, and P. DeCamilli (1981) Immunohistochemical localization of cyclic GMP-dependent protein kinase in mammalian brain. Proc. Natl. Acad. Sci. U. S. A. 78: 653-657.

Marshall, K. C., J. M. Wojtowicz, and W. J. Hendelman (1980) Patterns of functional synaptic connections in organized cultures of cerebellum. Neuroscience 5: 1847-1857.

McLaughlin, B., J. G. Wood, K. Saito, R. Barber, J. E. Vaughn, E. Roberts, and J. -Y Wu (1974) The fine structural localization of glutamate decarboxylase in synaptic terminals of rodent cerebellum. Brain Res. 76: 377-391.

Messer, A. (1977) The maintenance and identification of mouse cerebellar granule cells in monolayer culture. Brain Res. 130: $1-12$.

Mirsky, R., and E. J. Thompson (1975) Thy-1 (theta) antigen on the surface of morphologically distinct brain cell types. Cell 4: 95-101.

Mirsky, R., L. M. Wendon, P. Black, C. Stolkin, and D. Bray (1978) Tetanus toxin: A cell surface marker for neurones in culture. Brain Res. 148: 251-259.

Nelson, P. G., and J. H. Peacock (1973) Electrical activity in dissociated cell cultures from fetal mouse cerebellum. Brain Res. 61: 163-174.

Nilaver, G., R. Defendini, E. A. Zimmerman, M. C. Beinfield, and T. L. O'Donohue (1982) Motilin in the Purkinje cell of the cerebellum. Nature 295: 597-598.
Obata, K., M. Ito, R. Ochi, and N. Sato (1967) Pharmacological properties of the postsynaptic inhibition by Purkinje cell axons and the action of $\gamma$-aminobutyric acid on Dieters neurones. Exp. Brain Res. 4: 43-57.

Privat, A., and M. -J. Drian (1976) Postnatal maturation of rat Purkinje cells cultivated in the absence of two afferent systems: An ultrastructural study. J. Comp. Neurol. 166: 201244.

Pruss, R. M. (1979) Thy-1 antigen on astrocytes in long-term cultures of rat central nervous system. Nature 280: 688-690.

Raff, M. C., R. Mirsky, K. L. Fields, R. P. Lisak, S. H. Dorfman, D. H. Silberberg, N. A. Gregson, S. Liebowitz, and M. Kennedy (1978) Galactocerebroside: A specific cell surface antigen marker for oligodendrocytes in culture. Nature 273: 813816.

Raff, M. C., K. L. Fields, S. Hakomori, R. Mirsky, R. M. Pruss, and J. Winter (1979) Cell-type specific markers for distinguishing and studying neurons and the major classes of glial cells in culture. Brain Res. 174: 283-308.

Reif, A. E., and J. M. V. Allen (1964) The AKR thymic antigen and its distribution in leukemias and nervous tissues. J. Exp. Med. 120: 413-433.

Schengrund, C. -L., and P. T. Marangos (1980) Neuron-specific enolase levels in primary cultures of neurons. J. Neurosci. Res. 5: 305-311.

Schon, F., and J. S. Kelly (1975) Selective uptake of $\left[{ }^{3} \mathrm{H}\right] \beta$ alanine by glia: Association with the glial uptake system for GABA. Brain Res. 86: 243-257.

Seeds, N. W. (1973) Differentiation of aggregating brain cell cultures. In Tissue Culture of the Nervous System, G. Sato, ed., pp. 35-53, Plenum Press, New York.

Seil, F. J. (1979) Cerebellum in tissue culture. In Reviews of Neuroscience, D. M. Schneider, ed., Vol. 4, pp. 104-177, Raven Press, New York.

Sotelo, C., A. Privat, and M. -J Drian (1972) Localization of $\left[{ }^{3} \mathrm{H}\right] \mathrm{GABA}$ in tissue culture of rat cerebellum using electron microscopy. Brain Res. 45: 302-308.

Stern, P. L. (1973) $\theta$ alloantigen on mouse and rat fibroblasts. Nature New Biol. 246: 76-78.

Stohl, W., and N. K. Gonatas (1977) Distribution of the Thy-1 antigen in cellular and subcellular fractions of adult mouse brain. J. Immunol. 119: 422-427.

Trenkner, E., and R. L. Sidman (1977) Histogenesis of mouse cerebellum in microwell cultures. Cell reaggregation and migration, fiber and synapse formation. J. Cell Biol. 75: 915940.

Watanabe, M., T. Noguchi, and Y. Tsukada (1981) Regional cellular and subcellular distribution of Thy-1 antigen in rat nervous tissues. Neurochem. Res. 6: 507-512.

Williams, A. F., A. N. Barclay, M. Letarte-Muirhead, and R. J. Morris (1977) Rat Thy-1 antigens from thymus and brain: Their tissue distribution, purification and chemical composition. Cold Spring Harbor Symp. Quant. Biol. 41: 51-61.

Wolf, M. K. (1964) Differentiation of neuronal types and synapses in myelinating cultures of mouse cerebellum. J. Cell Biol. 22: 259-279.

Woodhams, P. L., J. Cohen, J. Mallet, and R. Balázs (1980) A preparation enriched in Purkinje cells identified by morphological and immunohistochemical criteria. Brain Res. 199: 435-442.

Yavin, Z., and E. Yavin (1974) Attachment and culture of dissociated cells from rat embryo cerebral hemispheres on polylysine coated surface. J. Cell Biol. 62: 540-546.

Zwerner, R. K., R. T. Acton, and N. W. Seeds (1977) The developmental appearance of Thy-1 in mouse reaggregating brain cell cultures. Dev. Biol. 60: 331-335. 